\title{
Chest X-ray and Etiological Orientations of Respiratory Diseases in Children Infected with Human Immunodeficiency Virus in a Pediatric Hospital in Ouagadougou (Burkina Faso)
}

\author{
Kouéta $\mathbf{F}^{1,5}$, Yonaba $\mathbf{C}^{4,5}$, Napon $\mathbf{A M}^{3,5}$, Kaboré $\mathbf{A}^{1,5}$, Ouédraogo $\mathbf{G}^{5,6}$, Ilboudo $\mathbf{R}^{2}$, Dao $\mathbf{L}^{1,5}$, Lougué/Sorgho LC $\mathbf{C}^{3,5}$, Yé $\mathbf{D}^{1,5}$ and Cissé $\mathbf{R}^{2,5}$ \\ ${ }^{1}$ Service de Pédiatrie médicale du Centre Hospitalier Universitaire Pédiatrique Charles de Gaulle, 01 BP 1198, Ouagadougou, Burkina Faso \\ ${ }^{2}$ Service d'imagerie médicale du Centre Hospitalier Universitaire Yalgado Ouédraogo, 03 BP 7022, Ouagadougou, Burkina Faso \\ ${ }^{3}$ Service d'imagerie médicale du Centre Hospitalier Universitaire Pédiatrique Charles de Gaulle, 01 BP 1198, Ouagadougou, Burkina Faso \\ ${ }^{4}$ Service de Pédiatrie du Centre Hospitalier Universitaire Yalgado Ouédraogo, 03 BP 7022, Ouagadougou, Burkina Faso \\ ${ }^{5}$ Unité de Formation et de Recherche en Sciences de la Santé (UFR/SDS), Université de Ouagadougou, 01 BP 1198 , Ouagadougou, Burkina Faso \\ ${ }^{6}$ Service de Pneumo-phtisiologie du Centre Hospitalier Universitaire Yalgado Ouédraogo, 03 BP 7022, Ouagadougou, Burkina Faso
}

*Corresponding author: Kouéta F, University of Ouagadougou, Ouagadougou, Burkina Faso, Tel: +33(0)55757 5051; E-mail:kouetafla@yahoo.com

Received date: January 22, 2015; Accepted date: July 27, 2015; Published date: August 3, 2015

Copyright: (C) 2015 Kouéta $\mathrm{F}$ et al. This is an open-access article distributed under the terms of the Creative Commons Attribution License, which permits unrestricted use, distribution, and reproduction in any medium, provided the original author and source are credited.

\begin{abstract}
To determine the etiologic orientations lung damage associated with HIV infection in children, we performed a prospective cross-sectional study in 91 patients followed at the Pediatric Hospital Charles de Gaulle to Ouagadougou from 1 January 2012 to 31 July 2013. It consisted in the clinical-radiological analysis of the different lesions observed before pulmonary call signs in children followed for HIV infection. The observed radiological lesions were most often diffuse and bilateral. This was broncho- pneumonia in $87.9 \%$ of cases and pleuro-pneumonia in $12.1 \%$ of cases. Parenchymal damages were dominated by interstitial opacities alveolar and alveolar-interstitial damages in respectively $29.7 \%, 24.2 \%$ and $12.1 \%$ of cases. The etiologies were mostly suspected bacterial pneumonia $(62.8 \%)$, lymphoid interstitial pneumonia $(17.6 \%)$, tuberculosis $(4.4 \%)$ and pneumocystosis $(3.3 \%)$. Chest radiography accessible to most patients should keep a place in the diagnostic approach. But in many cases it should be complemented with other complementary explorations in order to achieve a specific etiologic diagnosis and improve the treatment of pediatric AIDS.
\end{abstract}

Keywords: Chest X-ray; HIV; Child; Aetiologies; Burkina Faso

\section{Introduction}

Pulmonary diseases are prominently in the natural history of HIV infection of the child. Several African studies have shown that severe pneumonia is the leading cause of death in the pediatric AIDS [1-3]. These deaths would be linked to the severity of immunity deficiency in patients but especially the lack of further investigations leading to inefficient treatment $[1,2]$. In our hospital practice, lung diseases are common and often poor prognosis in children with HIV infection [4]. Knowledge of the respective share of the different lung diseases associated with HIV infection in these children may not only condition the strategy of the investigation to consider but also, and above all, guide the initial empirical therapeutic attitude to adopt. In the absence of systematic microbiological exploration, diagnosis is often presumptive and chest radiography plays a prominent place. A diagnostic approach based on the semiological and radiological analysis should lead to etiological directions and guide the therapeutic approach in pulmonary manifestations. Therefore, we found it useful to analyze the etiological orientations different clinico-radiological damage in a cohort of HIV-infected children followed at the Ouagadougou Pediatric University Hospital for improved management Pediatric AIDS in our context.

\section{Patients and Methods}

We conducted our study in the medical and imaging services of Charles de Gaulle Paediatric University Hospital (CHU Pédiatrique Charles de Gaulle- CHUP-CDG) and the imaging service of Yalgado Ouedraogo University Hospital (CHU Yalgado Ouédraogo CHUYO). This is a cross sectional descriptive and prospective study carried out from January $1^{\text {st }}, 2012$ to July $31^{\text {st }}, 2013$ on children infected with HIV and followed up at CHUP-CDG.

All children under 15 years of age, HIV infected, who had a respiratory sign and who were followed up at CHUP-CDG with a complete medical file, were included in the study. Each patient had a front chest X-ray done, completed if necessary, by a left profile incidence. All X-rays were subjected to two double blind interpretations by two radiologists respectively, working at CHUP$\mathrm{CDG}$ and $\mathrm{CHU}-\mathrm{YO}$. Lesions observed on X-ray negatives were classified into parenchymal lesions (interstitial and/or alveolar diseases), bronchial, mediastinal, pleural, parietal and vascular lesions. In case of discordance in interpretation, contribution from a third radiologist was required. However, in our study, the similarity factor was rated 1.

Variables were epidemiological, clinical, biological, and radiological data. The etiological discussion was held during a meeting between two radiologists and two pediatricians. Etiological orientations (common bacterial pulmonary infection, lymphoid interstitial pneumonia, pulmonary tuberculosis, pneumocystosis, and bronchitis) 
Citation: Kouéta F, Yonaba C, Napon AM, Kaboré A, Ouédraogo G, et al. (2015) Chest X-ray and Etiological Orientations of Respiratory Diseases in Children Infected with Human Immunodeficiency Virus in a Pediatric Hospital in Ouagadougou (Burkina Faso). Clinics Mother Child Health 12: 1000184. doi:10.4172/2090-7214.1000184

Page 2 of 5

were obtained by associating X-ray aspects to clinical data (fever, cough, dypnea, pulmonary auscultation signs) according to their more or less acute character. In some cases, the diagnosis was determined by bacteriological evidence or specific test treatment (against tuberculosis, high cotrimoxazole dosage). Therefore, assessment criteria of the response to treatment were clinical (continuous apyrexia, improvement of appetite, weight gain, disappearance of respiratory signs) and radiological (improvement of chest images). Parents' socio-economic status was broadly presumed regarding fathers' occupation and classified into two groups: the medium socioeconomic status including civil servants, liberal professions, traders, militaries, and para-militaries, and the low socio-economic status including farmers, cattle breeders, private sector workers, unemployed people, and students). Collected data were typed and analyzed by means of Epi-Info 3.3.2 software.

\section{Results}

\section{Epidemiological aspects}

Frequency of pulmonary diseases: During the period of the study, 91 HIV infected children out of 200 examined by a physician or admitted to hospital presented signs of pulmonary diseases, representing $45.5 \%$ of cases.

General characteristics of patients at the inclusion: The distribution of our patients according to the type of HIV noted 89 cases of HIV-1 (97.8\%), 1 case of HIV-2 and 1 case of HIV-1 and 2 co-infection. The general characteristics of patients as specified in Table 1 included $59.34 \%$ of boys and $40.66 \%$ of girls. Patients' average age was 60 months, with extremes varying from 12 to 180 months. The most represented age group was that of 30 to 60 months with 31 cases (34.1\%). Most patients (50.3\%) had a low socio-economic status. More than one thirds of patients $(38.5 \%)$ had lost at least one parent. According to WHO classification, $42 \%$ of patients were at stage IV, $52 \%$ at stage III and 6\% at stage II. Most children (94\%) were severely immune depressive (CD4 rate $<15 \%)$.

\begin{tabular}{|c|c|c|}
\hline General Characteristics & Number of cases & Percentage (\%) \\
\hline \multicolumn{3}{|l|}{ Gender } \\
\hline Male & 54 & 59.34 \\
\hline Female & 37 & 40.66 \\
\hline \multicolumn{3}{|l|}{ Age (months) } \\
\hline $0-30$ & 24 & 26.4 \\
\hline $31-60$ & 31 & 34.1 \\
\hline $61-90$ & 20 & 22 \\
\hline $91-120$ & 11 & 12 \\
\hline $121-180$ & 5 & 5.5 \\
\hline \multicolumn{3}{|l|}{ Socio-economic status } \\
\hline low & 46 & 50.3 \\
\hline Average & 45 & 49.7 \\
\hline \multicolumn{3}{|l|}{ Orphan status } \\
\hline Fatherless & 19 & 21 \\
\hline
\end{tabular}

\begin{tabular}{|l|l|l|}
\hline Motherless & 16 & 17.5 \\
\hline Fatherless and motherless & 7 & 7.7 \\
\hline Non orphans & \multicolumn{1}{|l|}{49} & 53.8 \\
\hline WHO clinical level & 7 & 7.7 \\
\hline Level II & \multicolumn{2}{|l|}{} \\
\hline Level III & 47 & 51.7 \\
\hline Level IV & 37 & 40.6 \\
\hline WHO immunological level & \multicolumn{2}{|l|}{} \\
\hline Level 3 & 11 & 12 \\
\hline Level 4 & 80 & 88 \\
\hline
\end{tabular}

Table 1: General characteristics of the 91 patients.

\begin{tabular}{|c|c|c|}
\hline Chest diseases & $\begin{array}{l}\text { Number of } \\
\text { cases }\end{array}$ & Percentage (\%) \\
\hline \multicolumn{3}{|l|}{ Parenchymal lesions } \\
\hline Interstitial & 27 & 29.7 \\
\hline Reticular & 2 & \\
\hline Micro-nodular & 7 & \\
\hline Reticular and micro-nodular & 18 & \\
\hline Alveolar & 43 & 47.2 \\
\hline Infiltrates & 22 & \\
\hline Pneumonia & 15 & \\
\hline Cavities & 2 & \\
\hline Blisters & 4 & \\
\hline Alveolar-interstitial & 7 & 7.7 \\
\hline Bronchial Diseases & 65 & 71.4 \\
\hline Pleural Diseases & 11 & 12 \\
\hline Mediastinal & 29 & 31 \\
\hline Cardiomegaly & 21 & \\
\hline Adenopathies & 8 & \\
\hline Vascular stasis & 1 & \\
\hline
\end{tabular}

Table 2: Distribution of chest diseases among the 91 patients.

\section{Clinical aspects}

The most frequent respiratory functional signs were cough (89\%), rhinorrhea (22\%), dypnea (14.3\%) and chest pains (8.8\%). Cough was associated to dypnea in five cases $(5.5 \%)$ and chest pain in six cases (6.6\%). At the physical level, crackling, subcrepitant and sonorous rales were observed respectively in $61.5 \%, 13.2 \%$ and $31.8 \%$ of cases. Pulmonary auscultation was normal in five cases (5.5\%) and fever was noted in $84.2 \%$ of cases. Extra-pulmonary signs were dominated by 
Citation: Kouéta F, Yonaba C, Napon AM, Kaboré A, Ouédraogo G, et al. (2015) Chest X-ray and Etiological Orientations of Respiratory Diseases in Children Infected with Human Immunodeficiency Virus in a Pediatric Hospital in Ouagadougou (Burkina Faso). Clinics Mother Child Health 12: 1000184. doi:10.4172/2090-7214.1000184

Page 3 of 5

lymphadenopathic syndrome (80.2\%), splenomegaly hepatomegaly $(7.7 \%)$ and parotiditis (5.5\%).

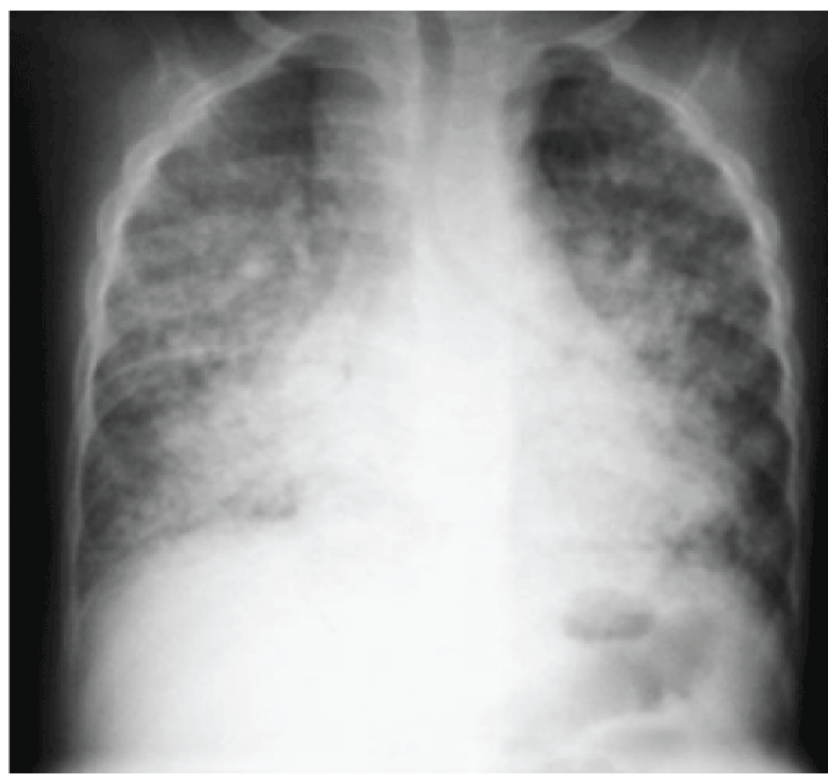

Figure 1: Broncho-pulmonary bilateral reticulo-micronodular disease, Miliary tuberculosis in 34 months children.

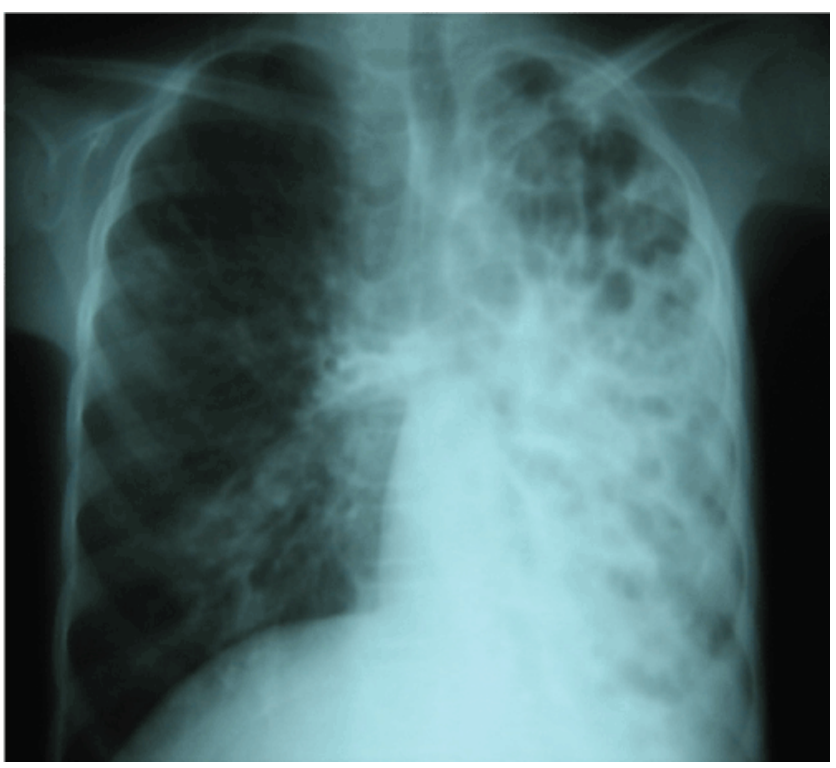

Figure 2: Bullous lung disease, pleuropulmonary staphylococcal infection in a 4 years child.

\section{$\mathrm{X}$-ray aspects}

Chest radiography objectified most often a combination of injuries including broncho-pneumonia in 80 cases (87.9\%) and pleuropneumonia in 11 cases $(12.1 \%)$. Parenchymal lesions was bilateral in $60.4 \%$ of cases and were dominated by interstitial opacities $(29.7 \%)$, alveolar damage (47.2\%) and alveolar-interstitial lesions (7.7\%) as shown in Table 2 and Figures 1-4. The observed mediastinal lesions were cardiomegaly (21 cases) and mediastinal adenopathies (eight cases).

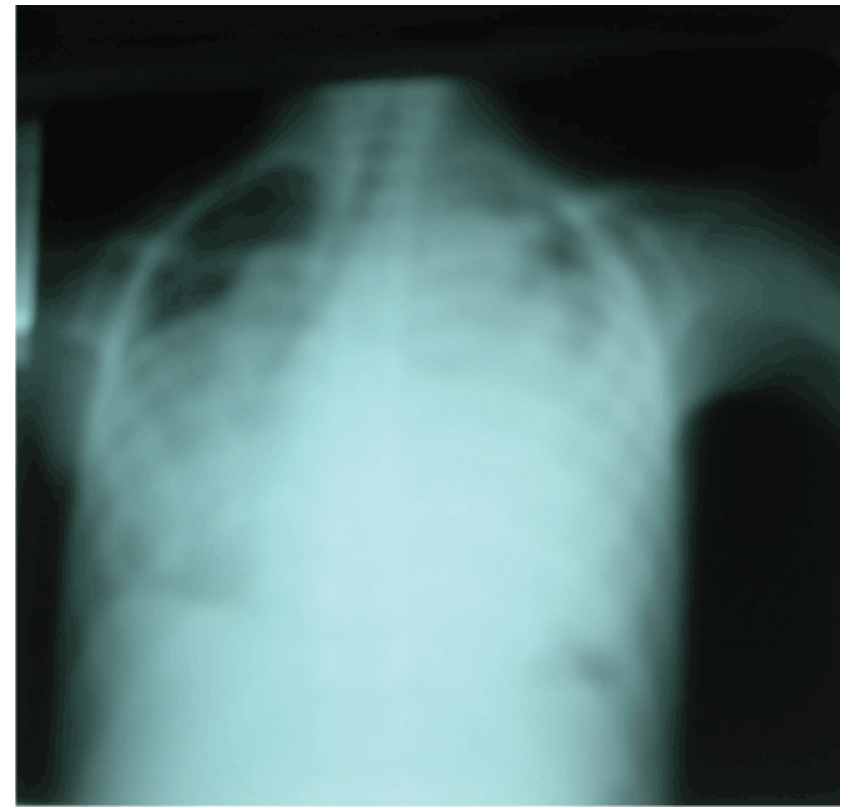

Figure 3: Bilateral pleurisy with a right apical pneumothorax, Pleuropulmonary staphylococcal infection in a 36 month child.

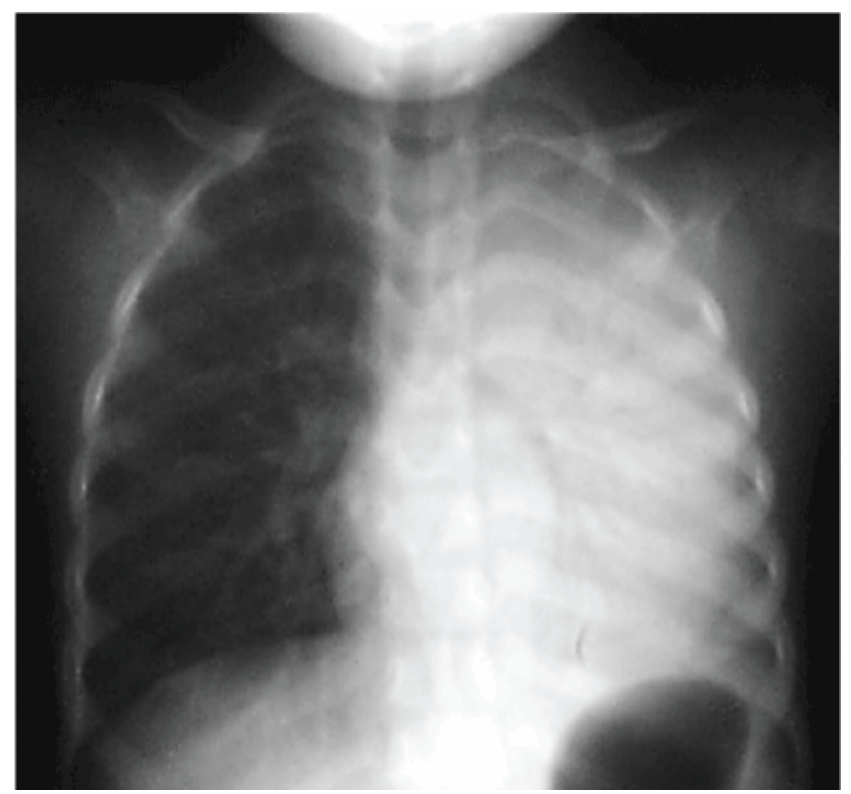

Figure 4: Massive left probable pneumococcal pneumonia in a 24month infant.

Etiological orientations of the various clinical and X-ray aspects: Suspected causes were dominated by bacterial pneumonia $(62.8 \%)$, lymphoid interstitial pneumonia (17.6\%), tuberculosis (4.4\%), and pneumocystis pneumonia (3.3\%) as specified on Table III. 
Citation: Kouéta F, Yonaba C, Napon AM, Kaboré A, Ouédraogo G, et al. (2015) Chest X-ray and Etiological Orientations of Respiratory Diseases in Children Infected with Human Immunodeficiency Virus in a Pediatric Hospital in Ouagadougou (Burkina Faso). Clinics Mother Child Health 12: 1000184. doi:10.4172/2090-7214.1000184

Page 4 of 5

Mycobacterium tuberculosis was isolated in two cases of pulmonary

TB suspicion and Staphylococcus aureus in three cases of pleurisy.

\begin{tabular}{|c|c|c|c|}
\hline Radiological aspects & Clinical symptoms & Suspected etiologies & Number of cases and percentage (\%) \\
\hline $\begin{array}{l}\text { Alveolar image } \\
\text { (Infiltrates, pneumonia) }\end{array}$ & $\begin{array}{l}\text { Fever, cough, dyspnea } \\
\text { Crackling or subcrepitants acute } \\
\text { evolution }\end{array}$ & Pneumonia common germs & $43(47.3)$ \\
\hline $\begin{array}{l}\text { Alveolar image ( bubbles ) and /or } \\
\text { pleural Image }\end{array}$ & $\begin{array}{l}\text { Fever, cough, dyspnea } \\
\text { Variable auscultation } \\
\text { Acute evolution }\end{array}$ & Staphylococcal pneumonia* & $15(15.5)$ \\
\hline $\begin{array}{l}\text { Alveolar image (caves ) } \pm \text { mediastinal } \\
\text { nodes } \\
\text { or } \\
\text { Image chronic interstitial pace (reticular } \\
\text { micronodular reticular micronodular ) } \pm \\
\text { lymphadenopathy médiastianles }\end{array}$ & $\begin{array}{l}\text { Fever, cough, dyspnea } \\
\text { Variable auscultation } \\
\text { Chronic evolution. }\end{array}$ & $\begin{array}{l}\text { Tuberculosis } \\
\text { pulmonary }^{\star *}\end{array}$ & $4(4.4)$ \\
\hline $\begin{array}{l}\text { Image of acute interstitial look } \\
\text { (reticular micronodular reticular } \\
\text { micronodular) }\end{array}$ & $\begin{array}{l}\text { Fever, intense dyspnea, hack. Often } \\
\text { normal auscultation Acute evolution }\end{array}$ & $\begin{array}{l}\text { Pneumonia } \\
\text { jiroveci pneumonia } \\
\text { or } \\
\text { viral pneumonia or intracellular bacteria }\end{array}$ & $\begin{array}{l}3(3.3) \\
6(6.6)\end{array}$ \\
\hline $\begin{array}{l}\text { Image chronic interstitial pace (reticular } \\
\text { micronodular reticular micronodular) }\end{array}$ & $\begin{array}{l}\text { Normal temperature, cough } \\
\text { Mild dyspnea.Often normal auscultation } \\
\text { Chronic evolution }\end{array}$ & $\begin{array}{l}\text { Lymphoid pneumonia } \\
\text { Interstitial }\end{array}$ & $16(17.6)$ \\
\hline Image isolated bronchial & $\begin{array}{l}\text { Low-grade fever, cough } \\
\text { Normal auscultation or rails sounding } \\
\text { Acute evolution }\end{array}$ & Viral or bacterial bronchitis & $4(4.4)$ \\
\hline \multicolumn{4}{|c|}{ * Staphylococcus aureus was isolated in 3 cases in pleural fluid } \\
\hline
\end{tabular}

Table 3: Etiological orientation of the various clinical and X-ray aspects among the 91 patients.

\section{Discussion}

In our study, the lack of bronchoalveolar lavage, molecular biology, and insufficient microbiological explorations have established some limits on the accuracy of the etiological diagnosis in most cases. The difficulty of establishing a precise etiological diagnosis of pulmonary involvement in resource-limited countries remains a constraint that justifies the prominence of the chest chest X-ray in the management of children infected with HIV. Our study allowed us to identify the clinical-radiological guidance lung damage child infected with HIV in our context and compare them with literature data.

\section{Epidemiological aspects}

The prevalence of respiratory diseases was $45.5 \%$ in our series. Although our rate is lower at $69.19 \%$ of lung damage observed by Akono, these data confirm the preponderance of lung disorders in HIV infection in children [1,2]. The median age of patients was 60 months with extremes of 12 and 180 months. The age group most affected age group was the 31 to 60 months. Our results corroborate those of Akono in Cameroon and in Senegal Mbaye Diack-[1,3]. This finding could be explained by the fact that in our countries, most children belong to the category of rapidly progressive forms, and does not generally exceed the age of 5 years without care. A male predominance was observed with $59.3 \%$ of cases as in most African studies [1-3]. This classic finding in the majority of infectious diseases in tropical paediatrics has no plausible explanation to date and could be related to increased susceptibility to infections boys. Over a third of our patients (38.5\%) was orphaned at least one parent. This reflects the drama of the pandemic for children infected or affected by HIV in Africa [5]. The loss of a parent increases the vulnerability of children who are already mostly from disadvantaged socioeconomic classes.

\section{$\mathrm{X}$-ray aspects}

In our patients, chest X-ray usually showed a combination of lesions including broncho-pneumonia in 80 cases (87.9\%) and pleuropneumonia in 11 cases (12.1\%). The parenchymal lesions were bilateral in $60.4 \%$ of cases and were dominated by interstitial opacities (29.7\%), alveolar infiltrates (24.2\%) and pneumonia (16.5\%). These same descriptions are found at varying frequencies by several other authors $[1,3,4,6,7]$. The severity and the polymorphism of pulmonary lesions observed not only reflect the diversity of the relevant etiologies but also by impairing the physiological mechanisms of cellular and humoral defense caused by HIV.

\section{Etiological orientations}

Pulmonary diseases in paediatric HIV infected population in subSaharan Africa are dominated by infectious diseases whose causes are 
Citation: Kouéta F, Yonaba C, Napon AM, Kaboré A, Ouédraogo G, et al. (2015) Chest X-ray and Etiological Orientations of Respiratory Diseases in Children Infected with Human Immunodeficiency Virus in a Pediatric Hospital in Ouagadougou (Burkina Faso). Clinics Mother Child Health 12: 1000184. doi:10.4172/2090-7214.1000184

Page 5 of 5

often difficult to confirm $[1,8]$. In our study, the germ was isolated in two cases of pulmonary tuberculosis and three cases of pleural and pulmonary staphyloccocia. Clinical and X-ray aspects allowed us to suspect respectively bacterial pneumopathies $(62,8 \%)$, lymphoid interstitial pneumonia (17.6\%), tuberculosis (4.4\%), and pneumocystosis (3.3\%). These etiologies were also reported by Akono in Cameroon [2] and Amon-Tanon-Dick [1] through a meta- analysis study on causes of pulmonary complications in sub-Saharan African HIV infected pediatric population. However, according to these authors, bacterial pneumopathies are first ranked followed respectively by pulmonary tuberculosis, pneumocystosis and lymphoid interstitial pneumonias. This frequency difference is attributable to diagnostic procedures. While alveolar lesions (infiltrates, pneumonia, and blisters) are very suspicious of community acquired germs, the etiological discussion is more delicate in interstitial lesions. Their correlations with clinical symptoms strengthen the suspected etiology. When a pulmonary interstitial disease is acute, it could be a viral infection or intracellular bacteria or Pneumocystis jiroveci even if the last one seems rare in Africa [9]. Bronchoalveolar lavage not yet practiced in our hospital would be of great diagnostic value $[10,11]$. When the course is chronic, there are two possibilities. In the absence of fever and serious dyspnea, lymphoid interstitial pneumonia is discussed. The presence of fever, serious general signs with acute respiratory distress and images of mediastinal lymphadenopathy, done evoked primary tuberculosis infection. High incidence of bacteriologically unconfirmed tuberculosis in HIV infected children in sub-Saharan Africa, adds an additional difficulty in the diagnosis of tuberculosis in a pediatric setting. Thus, the diagnosis of tuberculosis can be improved by repeated gastric aspirate which is more efficient than bronchoscopy [12]. New technics for detection and identification of tuberculosis bacillus which are Bactec culture [13] and PCR [14] are very expensive and therefore inaccessible to most developing countries.

\section{Conclusion}

Chest radiographic aspects in HIV infection in children are varied. The most suspected causes were in order of frequency: bacterial pneumonia, lymphoid interstitial pneumonia, tuberculosis and Pneumocystis jiroveci pneumonia. Chest radiography accessible to most patients should keep a place in the diagnostic approach by coupling to the semiotic analysis. But in many cases it should be complemented with other complementary explorations in order to achieve a specific etiologic diagnosis and improve the treatment of pediatric AIDS.

\section{References}

1. Akono-Zoua ME, Nko'O AS, Obama MTA, Kobela MM, Ondoua MM (2007) Atteintes pulmonaires dans l'infection à VIH chez l'enfant : aspects cliniques et radiologiques. Sidanet 4: 10-11.

2. Dick AF, Domoua K, N'Goan-Domoua AM, Msellati P (1998) Etiologies des complications pulmonaires du SIDA pédiatrique en Afrique subsaharienne. Med Mal Infect 28: 428-432.

3. Diack-Mbaye A, Signaté-Sy H, Diagne-Gueye NR, Ba A, Diouf S, et al. (2005) Aspects épidémiologiques et cliniques de l'infection à VIH de l'enfant au Centre Hospitalier National d'enfants Albert-Royer à Dakar. Arch Pédiatr 12: 404-409.

4. Kouéta F, Yé D, Dao L, Zoungrana-Kaboré A, Ouédraogo SAP, et al. (2008) Pneumopathies et infection VIH chez l'enfant au Centre Hospitalier Universitaire Pédiatrique Charles-de-Gaulle de Ouagadougou (Burkina Faso). Cahier Santé 18: 15-18.

5. Courpotin C, Conceicao D (2002) Prise en charge des enfants infectés par le VIH en Afrique Développement et Santé 162p.

6. Mabiala-Babela JR, Makosso E, Senga P (2008) Aspects radiographiques de la tuberculose pulmonaire chez l'enfant congolais : influence de l'infection à VIH. Méd Trop 68: 41-44.

7. Lacombe C, Lewin M, Monnier-Cholley L, Pacanowski J, Poirot JL, et al. (2007) [Imaging of thoracic pathology in patients with AIDS]. J Radiol 88: 1145-1154

8. Rudan I, Boschi-Pinto C, Biloglav Z, Mulholland K, Campbell H (2008) Epidemiology and etiology of childhood pneumonia. Bull World Health Organ 86: 408-416.

9. Hughes WT (1991) Pneumocystis carinii pneumonia: new approaches to diagnosis, treatment and prevention. Pediatr Infect Dis J 10: 391-399.

10. Albertini M, Bourrier T, Deville A, Sudaka I, Laffont C, et al. (1990) [Broncho-alveolar lavage in HIV-1 seropositive children]. Pediatrie 45: 895-900.

11. Birriel JA, Adams JA, Saldana MA, Mavunda K, Goldfinger S, et al. (1991) Role of flexible bronchoscopy and broncho-alveolar lavage in the diagnosis of pediatric acquired immunodeficiency syndrome-related pulmonary disease. Pediatrics 87: 897-899.

12. Somu N, Swaminathan S, Paramasivan CN, Vijayasekaran D, Chandrabhooshanam A, et al. (1995) Value of bronchoalveolar lavage and gastric lavage in the diagnosis of pulmonary tuberculosis in children. Tuber Lung Dis 76: 295-299.

13. Tertstra WJ (1990) Méthodes basées sur l'acide nucléique pour la détection des mycobactéries. Bull UICTMR65:70-3.

14. Eisenstein BI (1990) The polymerase chain reaction. A new method of using molecular genetics for medical diagnosis. N Engl J Med 322: 178-183. 